CLINICAL STUDY

\title{
Abnormal cardiac contractility in long-term exogenous subclinical hyperthyroid patients as demonstrated by two-dimensional echocardiography speckle tracking imaging
}

\author{
Randa M Abdulrahman ${ }^{1, *}$, Victoria Delgado ${ }^{2, *}$, Arnold C $\mathrm{T} \mathrm{Ng}^{2}$, See Hooi Ewe ${ }^{2}$, Matteo Bertini ${ }^{2}$, \\ Eduard R Holman ${ }^{2}$, Guido C Hovens ${ }^{1}$, Alberto M Pereira ${ }^{1}$, Johannes A Romijn ${ }^{1}$, Jeroen J Bax ${ }^{2}$ and Johannes W Smit $^{1}$ \\ Departments of ${ }^{1}$ Endocrinology and Metabolism, C4-R and ${ }^{2}$ Cardiology, C4-R, Leiden University Medical Center, PO Box 9600,2300 RC Leiden, \\ The Netherlands
}

(Correspondence should be addressed to J W Smit; Email: jwasmit@lumc.nl)

*(R M Abdulrahman and V Delgado contributed equally to this work)

\begin{abstract}
Background: Subclinical hyperthyroidism is associated with cardiovascular morbidity. Recent advances in echocardiography imaging have allowed sophisticated evaluation of myocardial tissue properties. Objective: To investigate the myocardial effects of long-term exogenous subclinical hyperthyroidism using two-dimensional speckle tracking echocardiography imaging (2D-STE).

Design: Prospective, single-blinded, placebo-controlled randomized trial of 6 months duration with two parallel groups.

Patients and methods: Totally 25 patients with a history of differentiated thyroid carcinoma on longterm TSH-suppressive levothyroxine ( $\left.\mathrm{L}_{-} \mathrm{T}_{4}\right)$ substitution were randomized to persistent TSH-suppressive $\mathrm{L}^{-\mathrm{T}_{4}}$ substitution (low-TSH group) or restoration of euthyroidism. Additionally 40 euthyroid controls were studied.

Results (proposal): At baseline, the group of patients showed normal left ventricular (LV) systolic function but impaired diastolic function as assessed with conventional echocardiographic parameters. Importantly, 2D-STE analysis demonstrated the presence of subclinical LV systolic and diastolic dysfunction with impaired circumferential and longitudinal strain and strain rate at the isovolumic relaxation time. After restoration of euthyroidism, a significant improvement in LV systolic and diastolic function as assessed with 2D-STE strain was observed.

Conclusion: Prolonged subclinical hyperthyroidism leads to systolic and diastolic dysfunction, which is reversible after restoration of euthyroidism. 2D-STE is a more sensitive technique to evaluate subtle changes in LV performance of these patients.
\end{abstract}

European Journal of Endocrinology 163 435-441

\section{Introduction}

Subclinical hyperthyroidism is a relatively common thyroid dysfunction with important cardiovascular consequences such as left ventricular (LV) diastolic dysfunction, increased LV mass, and increased risk of supraventricular arrhythmias (1-7). These cardiovascular effects can be accurately evaluated in exogenous subclinical hyperthyroidism, where the duration and development of thyroid dysfunction are well controlled, and different strategies to restore euthyroidism can be performed in a randomized fashion. We recently performed a prospective, randomized, placebocontrolled study in patients treated with total thyroidectomy for differentiated thyroid carcinoma, and demonstrated that 10-year thyroid hormone excess was related to increased LV mass index and overt diastolic dysfunction (7). More importantly, restoration of euthyroidism resulted in normalization of diastolic function.

Recent advances in echocardiography imaging have allowed sophisticated evaluation of myocardial tissue properties that may provide novel insights into the effects of thyroid hormone on the myocardium. Particularly, two-dimensional speckle tracking echocardiography (2D-STE) imaging is a novel technology that permits the study of multidirectional active deformation of the myocardium, providing comprehensive information on myocardial function and closely reflecting myocardial contractile properties (8-10). 2D-STE imaging allows estimation of both strain (radial, longitudinal, and circumferential) and strain rate (SR). Strain measures the myocardial fiber deformation (shortening and thickening), and SR measures the velocity of deformation. The present study explores further the effects of thyroid hormone on the 
myocardium with the use of 2D-STE and aimed to demonstrate whether LV mechanics, as assessed with multidirectional strain, are impaired in patients with subclinical hyperthyroidism and whether these abnormalities may be reversed after restoration of the euthyroid status. The echocardiographic data collected prospectively in the aforementioned randomized placebo-controlled study were reanalyzed in a blinded fashion with 2D-STE tracking echocardiography and compared with an expanded control group (7).

\section{Patients and methods}

The present study was a prospective single-blind randomized study of 6 months duration with two parallel groups. As previously described, the patient population consisted of athyreotic patients subjected to TSH-suppressive thyroxine $\left(\mathrm{T}_{4}\right)$ treatment $(7)$. Patients had been diagnosed with differentiated thyroid carcinoma and had been initially treated with total thyroidectomy and radioiodine ablative therapy. Cure was documented by the absence of measurable serum thyroglobulin during TSH stimulation and by a negative total-body scintigraphy with $4 \mathrm{mCi}^{131} \mathrm{I}$. TSH-suppressive therapy was defined by TSH levels below the lower reference value for normal serum levels of TSH $(0.4 \mathrm{mU} / \mathrm{l})$ for at least 10 years. After inclusion, the patients were randomized in a single-blind fashion to continuation of TSH-suppressive therapy (low-TSH group, with TSH target levels $<0.4 \mathrm{mU} / \mathrm{l}$ ) or restoration of euthyroidism by reducing the levo- $\mathrm{T}_{4}\left(\mathrm{~L}-\mathrm{T}_{4}\right)$ dose (euthyroid group, with TSH target levels within the normal reference range $0.40-0.48 \mathrm{mU} / \mathrm{l})$.

Physical examination, hormonal assessments, and comprehensive echocardiographic evaluation were performed at baseline and at 6 months follow-up. Changes in LV hemodynamics and performance were evaluated by conventional echocardiography and by sophisticated 2D-STE analyses. All echocardiographic analyses were performed by a single observer, blinded to treatment modalities.

The echocardiographic findings were compared with a control group of 40 individuals without cardiovascular morbidity: 8 males and 32 females with a mean age $46 \pm 8$ years. These controls were recruited from an echocardiographic database, as previously described (11). Those individuals with dilated LV, valvular heart disease, or hypertropic cardiomyopathy were excluded. Accordingly, the control group comprised individuals referred for atypical chest pain, palpitations, or syncope without murmur.

\section{Echocardiography}

Patients were imaged in the left lateral decubitus position using a commercially available system equipped with a $3.5 \mathrm{MHz}$ transducer (Vingmed Vivid-7, General
Electric Vingmed, Horten, Norway). Standard M-mode, two-dimensional, and color Doppler data were acquired triggered to the QRS complex and saved in cine loop format for off-line analysis (EchoPac 108.1.5, General Electric/Vingmed Ultrasound).

LV dimensions (end-diastolic diameters (EDD) and end-systolic diameters (ESD), end-diastolic interventricular septum thickness, and posterior wall thickness (PWT)), fractional shortening (FS), and LV ejection fraction (LVEF) were measured from M-mode recordings obtained at the parasternal long-axis views, according to the American Society of Echocardiography guidelines (12). LV mass was calculated by Devereux's formula and indexed to body surface area (LVMI) (13).

Diastolic function was evaluated by measuring the following parameters: E-wave, A-wave, E/A ratio, deceleration time (DT) of the E-wave, and isovolumic relaxation time (IVRT) obtained from the pulsed-wave Doppler recordings (14). Finally, left atrial volume was measured from the apical two- and four-chamber views as a morphologic marker of diastolic function.

\section{Two-dimensional speckle tracking strain echocardiography}

2D-STE analysis permits the angle-independent, multidirectional assessment of LV myocardial strain and SR. Both strain and SR characterize the LV tissue mechanical properties and differentiate the active myocardial contraction from the passive motion. Strain is a measure of myocardial deformation and is expressed as percentage $(\%)$, whereas SR indicates the rate of the myocardial deformation and is expressed as 1/s. 2D-STE analyses strain and SR by tracking frame-to-frame natural acoustic markers (so-called speckles), equally distributed within the myocardium and visible in the standard grayscale two-dimensional images. Accordingly, LV deformation can be studied along the cardiac cycle in three orthogonal directions as follows: radial, circumferential, and longitudinal (9). Radial and circumferential strains are assessed at the LV mid-ventricular short-axis images. Radial strain measured the thickening/thinning of the myocardial wall, whereas circumferential strain measures the myocardial shortening/lengthening along the curvature of the LV. The mid-ventricular short axis of the LV is divided into six segments, and the global values of radial and circumferential strains are derived from the average of the six segmental peak systolic strain values (Fig. 1, panels A and B). Longitudinal strain is measured at the apical two-chamber, four-chamber, and long-axis views. Longitudinal strain evaluates the shortening/lengthening of the myocardial wall, resulting from the movement of the mitral annulus plane upward/downward the LV apex. Each LV apical view is divided into six segments, and the global longitudinal strain value is derived from the average of the 18 segmental peak systolic strain values (Fig. 1, panel C) (10). Finally, global peak 


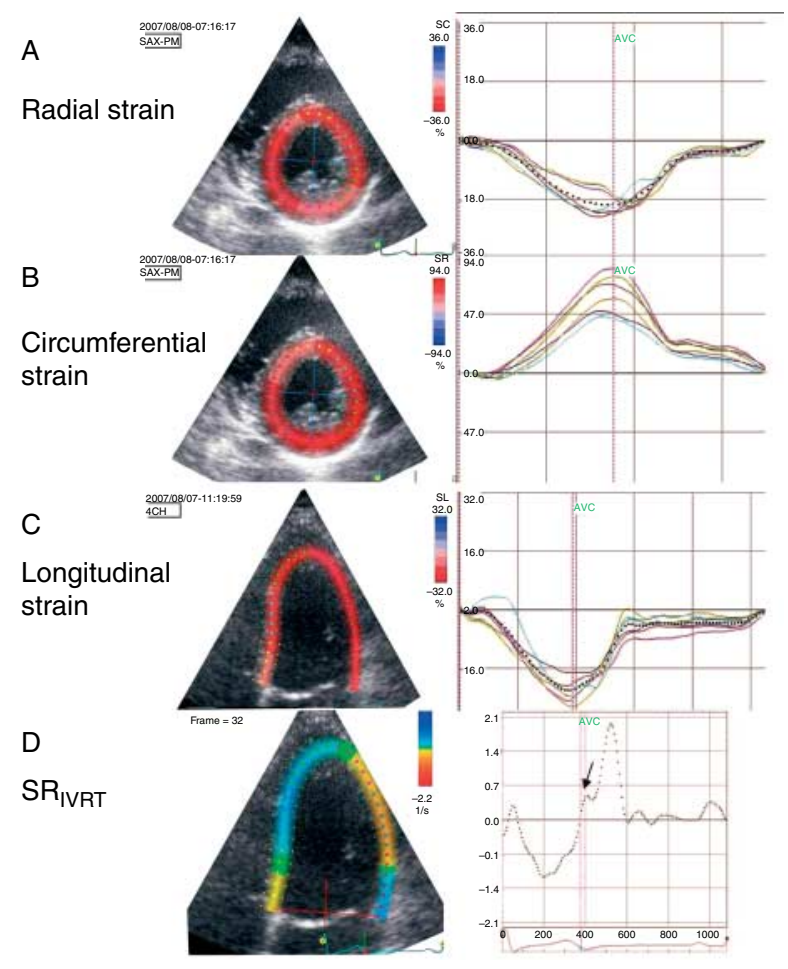

Figure 1 Two-dimensional speckle tracking strain imaging: multidirectional assessment of LV strain and strain rate. At the mid-ventricular short-axis view of the LV, radial (panel A) and circumferential (panel B) strains were calculated, obtaining the time-strain curves along the cardiac cycle for the six LV segments. Longitudinal strain of the LV is calculated at the apical four-chamber, two-chamber, and long-axis views (panel C).

Global longitudinal strain value is obtained from the average of 18 segments, and results are displayed in time-strain curves and polar map. Finally, $S_{\text {IVRT }}$ (panel $D$ ) is measured from the LV apical views as a parameter of LV relaxation. The arrow points out the value of strain rate at the isovolumic relaxation time.

longitudinal SR at the IVRT ( $\left.\mathrm{SR}_{\mathrm{IVRT}}\right)$ is measured at the three apical views and averaged for final analysis (Fig. 1, panel D), as previously described (15). This parameter is a marker of global myocardial relaxation and reflects the LV filling pressures. Therefore, in the present study, LV mechanical properties were evaluated through three systolic parameters (global radial, circumferential, and longitudinal strains) and one diastolic parameter $\left(\mathrm{SR}_{\mathrm{IVRT}}\right)$, all of them derived with 2D-STE imaging.

\section{Statistical analysis}

Continuous variables are presented as mean \pm s.D., and categorical variables are presented in number and frequencies. Comparisons between patients and controls were performed with Student's $t$-test for unpaired data. As previously described, the effects of different conditions on echocardiographic parameters were evaluated within and between low-TSH group and euthyroid patients using Mann-Whitney $U$ test and Wilcoxon sum rank test for unpaired and paired data respectively. To evaluate the relationship between free $\mathrm{T}_{4}$ and TSH levels and the various echocardiographic parameters, univariate regression analysis was performed. All statistical analyses were performed with SPSS software (version 16.0, SPSS Inc., Chicago, IL, USA). A $P$ value $<0.05$ was considered statistically significant.

\section{Results}

Out of an initial cohort of 33 patients, 25 patients were included in the present study (7). Thirteen patients continued TSH-suppressive therapy (low-TSH group, target TSH level $<0.4 \mathrm{mU} / \mathrm{l})$, whereas in the remaining 12 patients, the euthyroid status was restored (euthyroid group). At baseline, weight $((73.2 \pm 15.9$ (low-TSH group) vs $74.0 \pm 9.5 \mathrm{~kg}$ (euthyroid group), $P=0.881)$ ), systolic blood pressure $(135 \pm 23$ vs $134 \pm 14 \mathrm{mmHg}, P=0.920$ ), diastolic blood pressure $(81 \pm 10$ vs $83 \pm 5 \mathrm{mmHg}, P=0.728)$, heart rate ( $71 \pm 7$ vs $68 \pm 7$ bpm, $P=0.452), \mathrm{T}_{4}$ dose $(166 \pm 34$ vs $185 \pm 40 \mu \mathrm{g}, P=0.200)$, TSH $(0.054 \quad(<0.005-$ $0.339)$ vs $0.038(<0.005-0.302) \mathrm{mU} / \mathrm{l}, P=0.617)$, and free $\mathrm{T}_{4}(21.7 \pm 5.8 \mathrm{vs} 22.6 \pm 4.0 \mathrm{pmol} / \mathrm{l}, P=0.637)$ were not different between the low-TSH group and the euthyroid group. After 6 months, $\mathrm{T}_{4}$ dose $(177 \pm 33$ vs $129 \pm 37 \mu \mathrm{g}, P \leq 0.001)$, TSH concentrations $(0.015$ $(<0.005-0.347)$ vs $2.66 \quad(0.218-6.090) \mathrm{mU} / \mathrm{l}$, $P=0.001)$ and free $\mathrm{T}_{4}(23.1 \pm 1.1 \mathrm{vs} 18.5 \pm 1.1 \mathrm{pmol} / \mathrm{l}$, $P<0.001)$ differed significantly between the low-TSH group and the euthyroid group.

\section{Baseline echocardiography and 2D-STE analysis}

At baseline, patients showed significantly higher values of end-diastolic PWT and LV ESD than controls (Table 1). However, LV mass index (LVMI) was comparable between the two groups. In addition, patients had significantly lower values of LV FS and LVEF compared to the group of controls, but within the normal range (Table 1). Regarding the diastolic function, the group of patients showed significantly lower values of $\mathrm{E}$ - and $\mathrm{A}$-wave with an inverse $\mathrm{E} / \mathrm{A}$ ratio and significantly longer values of E-wave DT and IVRT, indicating impaired LV relaxation (Table 1). There were no differences in left atrial volume. Finally, 2D-STE analysis demonstrated a significant impairment of $\mathrm{LV}$ circumferential and longitudinal strains in the group of patients, whereas LV radial strain was preserved compared to the group of controls (Table 1). In addition, the $\mathrm{SR}_{\text {IVRT }}$ was significantly reduced in the group of patients compared to the group of controls, indicating higher LV filling pressures. 
Table 1 Baseline echocardiographic characteristics.

\begin{tabular}{|c|c|c|c|}
\hline & $\begin{array}{c}\text { Controls } \\
(n=40)\end{array}$ & $\begin{array}{c}\text { Patients } \\
(n=25)\end{array}$ & $P$ value \\
\hline LV mass index $\left(\mathrm{g} / \mathrm{m}^{2}\right)$ & $77.2 \pm 17.2$ & $86.0 \pm 21.0$ & 0.051 \\
\hline IVST (mm) & $8.4 \pm 1.0$ & $9.2 \pm 1.6$ & 0.056 \\
\hline PWT (mm) & $8.4 \pm 0.9$ & $9.2 \pm 1.2$ & 0.003 \\
\hline LV EDD (mm) & $49.4 \pm 4.7$ & $49.2 \pm 4.1$ & 0.989 \\
\hline LV ESD $(\mathrm{mm})$ & $28.8 \pm 4.5$ & $31.5 \pm 4.5$ & 0.020 \\
\hline LV FS (\%) & $41.4 \pm 6.1$ & $36.0 \pm 7.3$ & 0.004 \\
\hline LV EF (\%) & $71.6 \pm 7.1$ & $64.7 \pm 9.3$ & 0.002 \\
\hline E-wave $(\mathrm{cm} / \mathrm{s})$ & $72.9 \pm 17.6$ & $55.3 \pm 9.5$ & $<0.001$ \\
\hline A-wave $(\mathrm{cm} / \mathrm{s})$ & $56.7 \pm 12.6$ & $63.9 \pm 10.8$ & 0.029 \\
\hline E/A ratio & $1.3+0.2$ & $0.87+0.13$ & $<0.001$ \\
\hline E-wave DT (ms) & $191.1 \pm 33.3$ & $234 \pm 34$ & $<0.001$ \\
\hline IVRT (ms) & $77.7 \pm 13.3$ & $121.0 \pm 15.0$ & $<0.001$ \\
\hline Left atrial volume (ml) & $45.5 \pm 13.7$ & $50.5 \pm 13.7$ & 0.160 \\
\hline$E^{\prime}$-wave $(\mathrm{cm} / \mathrm{s})$ & $9.2 \pm 1.7$ & $5.7 \pm 1.3$ & $<0.001$ \\
\hline$A^{\prime}$-wave $(\mathrm{cm} / \mathrm{s})$ & $6.5 \pm 1.4$ & $6.8 \pm 1.4$ & 0.494 \\
\hline$E^{\prime} / A^{\prime}$ ratio & $1.4 \pm 0.5$ & $0.89 \pm 0.35$ & $<0.001$ \\
\hline Radial strain (\%) & $43.9+17.5$ & $42.3+11.8$ & 0.687 \\
\hline Circumferential strain (\%) & $-19.7 \pm 2.8$ & $-16.9 \pm 2.3$ & 0.001 \\
\hline Longitudinal strain (\%) & $-19.9 \pm 2.8$ & $-17.7 \pm 1.2$ & $<0.001$ \\
\hline $\mathrm{SR}_{\mathrm{IVRT}}(1 / \mathrm{s})$ & $0.39 \pm 0.09$ & $0.29 \pm 0.08$ & $<0.001$ \\
\hline
\end{tabular}

$\mathrm{DT}$, deceleration time; EDD, end-diastolic diameter; $\mathrm{EF}$, ejection fraction; ESD, end-systolic diameter; FS, fractional shortening; IVRT, isovolumic relaxation time; IVST, interventricular septum thickness; LV, left ventricular; PWT, posterior wall thickness; $\mathrm{SR}_{\mathrm{IVRT}}$, strain rate at the isovolumic relaxation time.

\section{Low-TSH group versus euthyroid group: conventional echocardiography}

At 6 months follow-up, the euthyroid group showed significant reductions in LV dimensions and improvements in LV FS and LVEF (Table 2). In addition, LV diastolic function improved significantly in the euthyroid group as indicated by a reduction in the A-wave velocity and normalization of the $\mathrm{E} / \mathrm{A}$ ratio, a significant reduction in the left atrial volume, and significant decreases in E-wave DT and IVRT. In contrast, the low-TSH group exhibited a significant increase in LV dimensions (EDDs and ESDs) and a significant reduction in LV FS and LVEF (Table 2). No changes in conventional imaging-derived LV diastolic parameters were observed in the low-TSH group.

\section{Low-TSH group versus euthyroid group: 2D-STE analysis}

At baseline, both groups of patients showed comparable values of LV radial, circumferential, and longitudinal strains and comparable values of $\mathrm{SR}_{\mathrm{IVRT}}$ as measured with 2D-STE imaging (Table 3).

At 6 months follow-up, the euthyroid group showed a significant improvement in LV circumferential and longitudinal strains and in $\mathrm{SR}_{\mathrm{IVRT}}$, whereas no changes in LV radial strain were observed (Fig. 2). In contrast, the low-TSH group did not have significant changes in multidirectional LV strain or $\mathrm{SR}_{\text {IVRT }}$ (Fig. 2). There were significant differences in changes in circumferential and longitudinal strains and in $\mathrm{SR}_{\mathrm{IVRT}}$ between the two groups (Table 3).

\section{Relationship between TSH levels and echocardiographic parameters at follow-up}

Univariate regression analysis was used to evaluate the influence of free $\mathrm{T}_{4}$ and TSH levels on different echocardiographic parameters (Table 4). Free $\mathrm{T}_{4}$ and TSH levels were not related to LV dimensions or systolic function as measured with conventional parameters. In contrast, some LV diastolic parameters as measured with transmitral pulsed-wave Doppler echocardiography (A-wave, E/A ratio, DT, and IVRT) or tissue Doppler

Table 2 Low-TSH group versus euthyroid group: conventional echocardiography and tissue Doppler imaging.

\begin{tabular}{|c|c|c|c|c|c|}
\hline & \multicolumn{2}{|c|}{ Low-TSH $(n=13)$} & \multicolumn{2}{|c|}{ Euthyroid $(n=12)$} & \multirow[b]{2}{*}{$P$ value $^{\mathrm{a}}$} \\
\hline & Baseline & 6 months & Baseline & 6 months & \\
\hline LV mass index $\left(\mathrm{g} / \mathrm{m}^{2}\right)$ & $86.0 \pm 26.0$ & $89.0 \pm 12.0$ & $87.0 \pm 16.0$ & $95.0 \pm 24.0$ & 0.468 \\
\hline IVST (mm) & $8.9 \pm 1.9$ & $9.2 \pm 1.1$ & $9.4 \pm 1.4$ & $10.0 \pm 1.6$ & 0.630 \\
\hline PWT (mm) & $9.0 \pm 1.2$ & $8.9 \pm 1.2$ & $9.5 \pm 1.3$ & $9.6 \pm 0.9$ & 0.763 \\
\hline LV EDD (mm) & $49.1 \pm 4.0$ & $52.1 \pm 3.3$ & $49.3 \pm 4.5$ & $48.6 \pm 3.3$ & 0.045 \\
\hline LV ESD $(\mathrm{mm})$ & $30.1 \pm 4.0$ & $34.1 \pm 5.4^{\star}$ & $33.1 \pm 4.8$ & $29.5 \pm 2.5^{\star}$ & $<0.001$ \\
\hline LV FS (\%) & $38.4 \pm 7.0$ & $34.8 \pm 8.0^{*}$ & $33.3 \pm 7.2$ & $39.4 \pm 3.8^{*}$ & $<0.001$ \\
\hline LV EF (\%) & $67.6 \pm 8.6$ & $62.6 \pm 11.4^{*}$ & $61.3 \pm 9.6$ & $69.8 \pm 4.6^{*}$ & $<0.001$ \\
\hline E-wave $(\mathrm{cm} / \mathrm{s})$ & $58.1 \pm 7.9$ & $58.9 \pm 8.2$ & $51.0 \pm 10.0$ & $54.8 \pm 13.3$ & 0.353 \\
\hline A-wave $(\mathrm{cm} / \mathrm{s})$ & $66.1 \pm 11.2$ & $67.7 \pm 12.4$ & $61.3 \pm 10.6$ & $47.4 \pm 11.6^{*}$ & $<0.001$ \\
\hline E/A ratio & $0.91 \pm 0.16$ & $0.88 \pm 0.12$ & $0.83 \pm 0.10$ & $1.18 \pm 0.27^{*}$ & $<0.001$ \\
\hline E-wave DT (ms) & $230 \pm 34$ & $236 \pm 26$ & $237 \pm 38$ & $196 \pm 24^{*}$ & 0.001 \\
\hline IVRT (ms) & $115 \pm 15$ & $121 \pm 17$ & $127 \pm 13$ & $95 \pm 15^{\star}$ & $<0.001$ \\
\hline Left atrial volume (ml) & $48.6 \pm 14.7$ & $50.7 \pm 17.4$ & $52.0 \pm 12.4$ & $44.9 \pm 12.4^{*}$ & 0.009 \\
\hline $\mathrm{E}^{\prime}$-wave $(\mathrm{cm} / \mathrm{s})$ & $5.9 \pm 1.8$ & $5.2 \pm 1.8$ & $5.5 \pm 0.6$ & $7.2 \pm 1.3^{*}$ & $<0.001$ \\
\hline $\mathrm{A}^{\prime}$-wave $(\mathrm{cm} / \mathrm{s})$ & $6.4 \pm 1.4$ & $5.7 \pm 1.5$ & $7.1 \pm 1.4$ & $6.7 \pm 1.6$ & 0.493 \\
\hline$E^{\prime} / A^{\prime}$ ratio & $0.97 \pm 0.42$ & $0.97 \pm 0.34$ & $0.81 \pm 0.26$ & $1.13 \pm 0.34^{*}$ & 0.003 \\
\hline
\end{tabular}

DT, deceleration time; EDD, end-diastolic diameter; EF, ejection fraction; ESD, end-systolic diameter; FS, fractional shortening; IVRT, isovolumic relaxation time; IVST, interventricular septum thickness; LV, left ventricular; PWT, posterior wall thickness. ${ }^{*} P<0.05$ versus baseline (within the groups).

${ }^{a}$ Difference between 6 months and baseline, euthyroid versus low-TSH group. 
Table 3 Low-TSH group versus euthyroid group: two-dimensional speckle tracking strain imaging.

\begin{tabular}{|c|c|c|c|c|c|}
\hline & \multicolumn{2}{|c|}{ Low-TSH $(n=13)$} & \multicolumn{2}{|c|}{ Euthyroid $(n=12)$} & \multirow[b]{2}{*}{$\boldsymbol{P}$ value } \\
\hline & Baseline & 6 months & Baseline & 6 months & \\
\hline Radial strain (\%) & $42.9 \pm 10.2$ & $39.7 \pm 13.7$ & $41.7 \pm 13.7$ & $42.0 \pm 11.2$ & 0.431 \\
\hline Circumferential strain (\%) & $-17.0 \pm 2.8$ & $-16.5 \pm 1.3$ & $-16.9 \pm 1.7$ & $-18.8 \pm 2.3^{\star}$ & 0.018 \\
\hline Longitudinal strain (\%) & $-17.9 \pm 1.3$ & $-17.5 \pm 1.8$ & $-17.5 \pm 1.1$ & $-19.7 \pm 2.1^{*}$ & 0.001 \\
\hline $\operatorname{SR}_{\mathrm{IVRT}}(1 / \mathrm{s})$ & $0.29 \pm 0.1$ & $0.28 \pm 0.08$ & $0.29 \pm 0.06$ & $0.42 \pm 0.09^{*}$ & 0.004 \\
\hline
\end{tabular}

$\mathrm{SR}_{\mathrm{IVRT}}$, strain rate at the isovolumic relaxation time. ${ }^{\star} P<0.05$ versus baseline (within the groups).

a Difference between 6 months and baseline, euthyroid versus low-TSH group.

imaging ( $\mathrm{E}^{\prime}$-wave) were significantly related to free $\mathrm{T}_{4}$ and TSH levels. Finally, novel indices of LV systolic function based on 2D-STE analysis showed a borderline association with TSH levels but not with free $\mathrm{T}_{4}$ levels.

\section{Discussion}

The present study provides new insights into the effects of thyroid hormone on myocardial mechanical performance assessed with 2D-STE. In patients with long-term exogenous subclinical hyperthyroidism and preserved LVEF, 2D-STE analysis demonstrated the presence of impaired LV myocardial deformation. After restoration of euthyroid status, a significant improvement in circumferential and longitudinal strains and $\mathrm{SR}_{\text {IVRT }}$ was observed. Therefore, in patients with exogenous subclinical hyperthyroidism and preserved LVEF, the excess of thyroid hormone exerts a deleterious effect on myocardial function that is reversible upon restoration of euthyroid status. It remains to be
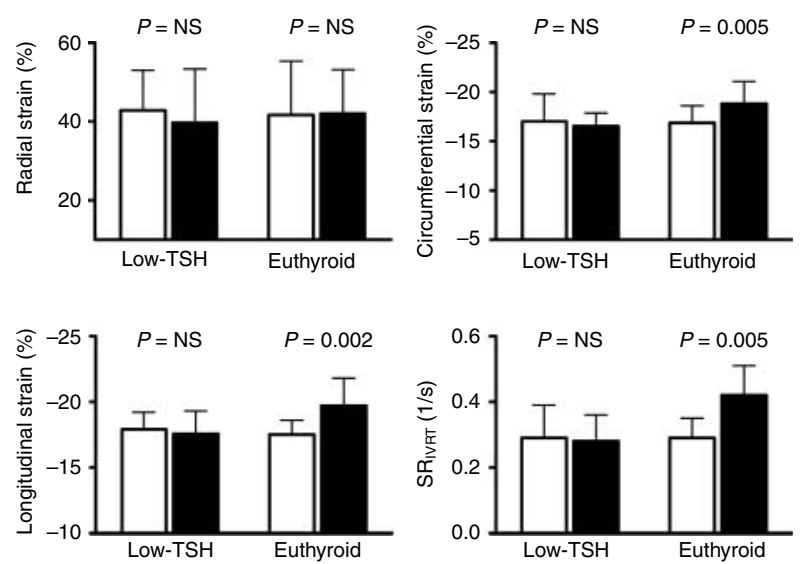

Figure 2 Changes in multidirectional LV strain and SR $\mathrm{IVRT}_{\mathrm{InT}}$ in lowTSH and euthyroid groups. The bar graphs show multidirectional LV strain and strain rate values at baseline (white bars) and follow-up (solid bars) in the low-TSH group and the euthyroid group. In those patients who continued TSH-suppressive therapy, there were no changes in multidirectional LV strain and strain rate at the isovolumic relaxation time (SR $\left.\mathrm{SRRT}_{\mathrm{VVT}}\right)$. In contrast, those patients with restoration of the euthyroid status showed significant improvements in circumferential and longitudinal strains and in SR $\mathrm{R}_{\text {IVRT }}$. determined whether these changes may be reversed or not once overt heart failure is present.

The cardiovascular effects of subclinical hyperthyroidism have been well documented, and include increased LV mass, diastolic dysfunction, and increased risk of cardiac arrhythmias $(1-6,16)$. However, it is important to note that previous studies included retrospective series and yielded observational and controversial results $(4,16-18)$. In contrast, the randomized design of the present study permitted evaluation of the direct cardiovascular effects of thyroid hormone. Patients with subclinical hyperthyroidism showed impaired diastolic function as assessed with conventional pulsed-wave Doppler echocardiography and tissue Doppler imaging (7). After restoration of euthyroid hormone levels, significant improvements in diastolic function were observed. The present study represents a step further in the characterization of $\mathrm{LV}$ diastolic performance by evaluating the relaxation properties of the myocardium with 2D-STE. At baseline, the overall population showed a reduced $\mathrm{SR}_{\mathrm{IVRT}}$, a surrogate of increased LV filling pressures (15). Improvement in LV filling pattern with an increase in $\mathrm{SR}_{\text {IVRT }}$ was only observed in those patients with restored euthyroidism, whereas in those patients with low-TSH levels, $S_{\text {IVRT }}$ remained unchanged. The measurement of $\mathrm{SR}_{\text {IVRT }}$ provides additional insight to previous findings based on tissue Doppler imaging, as this parameter may be less load-dependent and relies on active deformation of the myocardium. In addition, these changes in LV diastolic dysfunction were independent of LV mass. The present study population had an increased LV mass as compared with controls. However, most patients did not show LV hypertrophy. As previously demonstrated, thyroid hormone exerts direct effects on myocardial diastolic relaxation independent of protein synthesis and cardiac growth $(1,19)$. Therefore, it may reflect more the direct biochemical effects of thyroid hormone on the myocardium, which lead to activation of local signal transduction pathways rather than the effects of $\mathrm{LV}$ hypertrophy $(1,20)$. In earlier studies, more profound LV hypertrophy was found that was reversed by $\beta$-blockers $(5,21,22)$ or dose reduction (23). These studies also included patients with multinodular goiter, who may have been exposed to higher levels of 
Table 4 Univariate regression analysis between free thyroxine $\left(T_{4}\right)$ and TSH levels and echocardiographic parameters at follow-up.

\begin{tabular}{|c|c|c|c|c|c|c|}
\hline & \multicolumn{3}{|c|}{$\mathbf{T}_{4}(\mathrm{pmol} / \mathrm{l})$} & \multicolumn{3}{|c|}{ TSH (mU/l) } \\
\hline & $\beta$ & $\begin{array}{l}95 \% \text { confidence } \\
\text { interval }\end{array}$ & $P$ value & $\beta$ & $\begin{array}{l}\text { 95\% confidence } \\
\text { interval }\end{array}$ & $P$ value \\
\hline LV mass index $\left(\mathrm{g} / \mathrm{m}^{2}\right)$ & 0.286 & -0.770 to 3.294 & 0.209 & 0.176 & -1.746 to 4.113 & 0.411 \\
\hline IVST (mm) & 0.148 & -0.100 to 0.190 & 0.521 & 0.174 & -0.166 to 0.385 & 0.827 \\
\hline PWT (mm) & 0.067 & -0.095 to 0.126 & 0.774 & 0.232 & -0.097 to 0.325 & 0.275 \\
\hline LV EDD (mm) & 0.126 & -0.295 to 0.508 & 0.586 & 0.138 & -0.813 to 0.424 & 0.521 \\
\hline LV ESD (mm) & 0.120 & -0.405 to 0.676 & 0.606 & 0.335 & -1.486 to 0.161 & 0.109 \\
\hline LV FS (\%) & 0.089 & -0.870 to 0.597 & 0.701 & 0.324 & -0.278 to 2.188 & 0.123 \\
\hline LV EF (\%) & 0.094 & -1.250 to 0.839 & 0.685 & 0.331 & -0.362 to 3.132 & 0.114 \\
\hline E-wave $(\mathrm{cm} / \mathrm{s})$ & 0.037 & -1.243 to 1.067 & 0.875 & 0.103 & -2.741 to 1.697 & 0.630 \\
\hline A-wave $(\mathrm{cm} / \mathrm{s})$ & 0.438 & -2.924 to -0.020 & 0.047 & 0.672 & -12.672 to -4.376 & $<0.001$ \\
\hline E/A ratio & 0.413 & -0.001 to 0.043 & 0.063 & 0.587 & -6.911 to -1.677 & 0.003 \\
\hline E-wave DT (ms) & 0.112 & -2.692 to 4.351 & 0.628 & 0.575 & 0.025 to 0.110 & 0.003 \\
\hline IVRT (ms) & 0.153 & -2.593 to 1.327 & 0.507 & 0.459 & -7.747 to -0.597 & 0.024 \\
\hline Left atrial volume (ml) & 0.407 & -2.316 to 0.088 & 0.067 & 0.030 & -3.285 to 2.871 & 0.890 \\
\hline $\mathrm{E}^{\prime}$-wave $(\mathrm{cm} / \mathrm{s})$ & 0.461 & 0.012 to 0.308 & 0.036 & 0.446 & 0.040 to 0.665 & 0.029 \\
\hline $\mathrm{A}^{\prime}$-wave $(\mathrm{cm} / \mathrm{s})$ & 0.191 & -0.102 to 0.241 & 0.407 & 0.230 & -0.147 to 0.484 & 0.289 \\
\hline$E^{\prime} / A^{\prime}$ ratio & 0.231 & -0.012 to 0.036 & 0.313 & 0.213 & -0.033 to 0.097 & 0.319 \\
\hline Radial strain (\%) & 0.152 & -1.061 to 1.970 & 0.535 & 0.386 & -0.202 to 4.937 & 0.069 \\
\hline Circumferential strain (\%) & 0.044 & -0.246 to 0.207 & 0.857 & 0.389 & -0.837 to 0.030 & 0.067 \\
\hline Longitudinal strain (\%) & 0.243 & -0.270 to 0.085 & 0.288 & 0.377 & -0.760 to 0.031 & 0.069 \\
\hline $\mathrm{SR}_{\text {IVRT }}(1 / \mathrm{s})$ & 0.035 & -0.011 to 0.012 & 0.879 & 0.298 & -0.006 to 0.035 & 0.157 \\
\hline
\end{tabular}

DT, deceleration time; EDD, end-diastolic diameter; EF, ejection fraction; ESD, end-systolic diameter; FS, fractional shortening; IVRT, isovolumic relaxation time; IVST, interventricular septum thickness; LV, left ventricular; PWT, posterior wall thickness.

free $\mathrm{T}_{4}$ and have subsequently shown more profound myocardial hypertrophy.

It can be hypothesized that the fact that we did not find a significant difference between patients and controls in LVMI and IVST could be explained by the fact that TSH levels were not suppressed in all patients. We therefore compared IVST and LVMI between patients with completely suppressed TSH levels at baseline and patients with TSH $\geq 0.1 \mathrm{mU} / \mathrm{l}$, but did not find significant differences between these two groups.

The most insightful finding of the present study is, perhaps, the presence of subclinical LV systolic dysfunction as assessed by means of multidirectional strain. In patients with subclinical hyperthyroidism, the prevalence of overt LV systolic dysfunction as assessed with conventional two-dimensional echocardiography ( $\mathrm{LVEF}<45 \%$ ) is rather low (2.4\%) (24). However, it has been shown that despite preserved or even increased LVEF at rest, patients with thyroid hormone excess may have impaired LV contractile reserve with no further increase in LVEF during exercise (25). Myocardial strain analysis based on 2D-STE may be a more sensitive tool than conventional measurements of systolic LV function, as it provides information on active deformation of the myocardium. In addition, this imaging tool enables the evaluation of subtle changes in myocardial strain after restoration of euthyroidism, as demonstrated in the present study.

These findings may have important clinical implications as long-term subclinical hyperthyroidism has been related to increased incidence of cardiovascular events (6). The tight control of thyroid hormone levels with restoration of euthyroidism may help to improve the cardiovascular risk profile of these patients and therefore may reduce the risk of cardiovascular events. In this regard, 2D-STE may allow refining the therapy of this group of patients.

Some limitations have to be acknowledged. First, the assessment of LV myocardial function with 2D-STE analysis after an acute change of TSH or free $\mathrm{T}_{4}$ was not performed, and therefore the effects of these hormones at the tissue level could not be elucidated. In addition, the small study population may preclude us from observing stronger relationships between the 2D-STEderived parameters of LV function and TSH levels.

In conclusion, patients with prolonged subclinical hyperthyroidism show subtle LV systolic and diastolic dysfunction, which is reversible after restoration of euthyroidism.

\section{Declaration of interest}

The authors declare that there is no conflict of interest that could be perceived as prejudicing the impartiality of the research reported.

\section{Funding}

This research did not receive any specific grant from any funding agency in the public, commercial, or not-for-profit sector.

\section{References}

1 Polikar R, Burger AG, Scherrer U \& Nicod P. The thyroid and the heart. Circulation 199387 1435-1441. 
2 Biondi B, Fazio S, Carella C, Amato G, Cittadini A, Lupoli G, Sacca L, Bellastella A \& Lombardi G. Cardiac effects of long term thyrotropin-suppressive therapy with levothyroxine. Journal of Clinical Endocrinology and Metabolism 199377 334-338. (doi:10. 1210/jc.77.2.334)

3 Biondi B, Palmieri EA, Klain M, Schlumberger M, Filetti S \& Lombardi G. Subclinical hyperthyroidism: clinical features and treatment options. European Journal of Endocrinology 2005 152 1-9. (doi:10.1530/eje.1.01809)

4 Biondi B, Palmieri EA, Fazio S, Cosco C, Nocera M, Saccà L, Filetti S, Lombardi G \& Perticone F. Endogenous subclinical hyperthyroidism affects quality of life and cardiac morphology and function in young and middle-aged patients. Journal of Clinical Endocrinology and Metabolism $2000 \mathbf{8 5} 4701-4705$. (doi:10.1210/jc.85.12.4701)

5 Fazio S, Biondi B, Carella C, Sabatini D, Cittadini A, Panza N, Lombardi G \& Sacca L. Diastolic dysfunction in patients on thyroidstimulating hormone suppressive therapy with levothyroxine: beneficial effect of beta-blockade. Journal of Clinical Endocrinology and Metabolism $1995 \mathbf{8 0}$ 2222-2226. (doi:10.1210/jc.80.7. 2222)

6 Cappola AR, Fried LP, Arnold AM, Danese MD, Kuller LH, Burke GL, Tracy RP \& Ladenson PW. Thyroid status, cardiovascular risk, and mortality in older adults. Journal of the American Medical Association 2006295 1033-1041. (doi:10.1001/jama. 295.9.1033)

7 Smit JW, Eustatia-Rutten CF, Corssmit EP, Pereira AM, Frölich M, Bleeker GB, Holman ER, van der Wall EE, Romijn JA \& Bax JJ. Reversible diastolic dysfunction after long-term exogenous subclinical hyperthyroidism: a randomized, placebo-controlled study. Journal of Clinical Endocrinology and Metabolism 200590 6041-6047. (doi:10.1210/jc.2005-0620)

8 Leitman M, Lysyansky P, Sidenko S, Shir V, Peleg E, Binenbaum M, Kaluski E, Krakover R \& Vered Z. Two-dimensional strain - a novel software for real-time quantitative echocardiographic assessment of myocardial function. Journal of the American Society of Echocardiography 200417 1021-1029. (doi:10.1016/j.echo. 2004.06.019)

9 Amundsen BH, Helle-Valle T, Edvardsen T, Torp H, Crosby J, Lyseggen E, Stoylen A, Ihlen H, Lima JA, Smiseth OA \& Slordahl SA. Noninvasive myocardial strain measurement by speckle tracking echocardiography: validation against sonomicrometry and tagged magnetic resonance imaging. Journal of the American College of Cardiology 200647 789-793. (doi:10.1016/j.jacc.2005.10.040)

10 Delgado V, Mollema SA, Ypenburg C, Tops LF, van der Wall EE, Schalij MJ \& Bax JJ. Relation between global left ventricular longitudinal strain assessed with novel automated function imaging and biplane left ventricular ejection fraction in patients with coronary artery disease. Journal of the American Society of Echocardiography 200821 1244-1250. (doi:10.1016/j.echo. 2008.08.010)

11 Pereira AM, van Thiel SW, Lindner JR, Roelfsema F, van der Wall EE, Morreau H, Smit JW, Romijn JA \& Bax JJ. Increased prevalence of regurgitant valvular heart disease in acromegaly. Journal of Clinical Endocrinology and Metabolism 200489 71-75. (doi:10.1210/jc.2003-030849)

12 Lang RM, Bierig M, Devereux RB, Flachskampf FA, Foster E, Pellikka PA, Picard MH, Roman MJ, Seward J, Shanewise JS, Solomon SD, Spencer KT, Sutton MS \& Stewart WJ. Recommendations for chamber quantification: a report from the American Society of Echocardiography's Guidelines and Standards Committee and the Chamber Quantification Writing Group, developed in conjunction with the European Association of Echocardiography, a branch of the European Society of Cardiology. Journal of the American Society of Echocardiography $2005 \mathbf{1 8}$ 1440-1463. (doi:10.1016/j.echo.2005.10.005)

13 Devereux RB, Alonso DR, Lutas EM, Gottlieb GJ, Campo E, Sachs I \& Reichek N. Echocardiographic assessment of left ventricular hypertrophy: comparison to necropsy findings. American Journal of $\begin{array}{lllll}\text { Cardiology } & 1986 & \mathbf{5 7} & 450-458 . & \text { (doi:10.1016/0002-9149 }\end{array}$ (86)90771-X)

14 Quinones MA, Otto CM, Stoddard M, Waggoner A \& Zoghbi WA. Recommendations for quantification of Doppler echocardiography: a report from the Doppler Quantification Task Force of the Nomenclature and Standards Committee of the American Society of Echocardiography. Journal of the American Society of Echocardiography 200215 167-184. (doi:10.1067/mje.2002. 120202)

15 Dokainish H, Sengupta R, Pillai M, Bobek J \& Lakkis N. Usefulness of new diastolic strain and strain rate indexes for the estimation of left ventricular filling pressure. American Journal of Cardiology 2008101 1504-1509. (doi:10.1016/j.amjcard.2008.01.037)

16 Iqbal A, Schirmer H, Lunde P, Figenschau Y, Rasmussen K \& Jorde R. Thyroid stimulating hormone and left ventricular function. Journal of Clinical Endocrinology and Metabolism 2007 92 3504-3510. (doi:10.1210/jc.2007-0727)

17 Shapiro LE, Sievert R, Ong L, Ocampo EL, Chance RA, Lee M, Nanna M, Ferrick K \& Surks MI. Minimal cardiac effects in asymptomatic athyreotic patients chronically treated with thyrotropin-suppressive doses of L-thyroxine. Journal of Clinical Endocrinology and Metabolism 199782 2592-2595. (doi:10. $1210 /$ jc.82.8.2592)

18 Shargorodsky M, Serov S, Gavish D, Leibovitz E, Harpaz D \& Zimlichman R. Long-term thyrotropin-suppressive therapy with levothyroxine impairs small and large artery elasticity and increases left ventricular mass in patients with thyroid carcinoma. Thyroid 200616 381-386. (doi:10.1089/thy.2006.16.381)

19 Ojamaa K, Samarel AM, Kupfer JM, Hong C \& Klein I. Thyroid hormone effects on cardiac gene expression independent of cardiac growth and protein synthesis. American Journal of Physiology 1992 263 E534-E540.

20 Fazio S, Palmieri EA, Lombardi G \& Biondi B. Effects of thyroid hormone on the cardiovascular system. Recent Progress in Hormone Research 200459 31-50. (doi:10.1210/rp.59.1.31)

21 Biondi B, Fazio S, Carella C, Sabatini D, Amato G, Cittadini A, Bellastella A, Lombardi G \& Sacca L. Control of adrenergic overactivity by beta-blockade improves the quality of life in patients receiving long term suppressive therapy with levothyroxine. Journal of Clinical Endocrinology and Metabolism $1994 \mathbf{7 8}$ 1028-1033. (doi:10.1210/jc.78.5.1028)

22 Biondi B, Fazio S, Cuocolo A, Sabatini D, Nicolai E, Lombardi G, Salvatore M \& Sacca L. Impaired cardiac reserve and exercise capacity in patients receiving long-term thyrotropin suppressive therapy with levothyroxine. Journal of Clinical Endocrinology and Metabolism 199681 4224-4228. (doi:10.1210/jc.81.12.4224)

23 Mercuro G, Panzuto MG, Bina A, Leo M, Cabula R, Petrini L, Pigliaru F \& Mariotti S. Cardiac function, physical exercise capacity, and quality of life during long-term thyrotropinsuppressive therapy with levothyroxine: effect of individual dose tailoring. Journal of Clinical Endocrinology and Metabolism 200085 159-164. (doi:10.1210/jc.85.1.159)

24 Rodondi N, Bauer DC, Cappola AR, Cornuz J, Robbins J, Fried LP, Ladenson PW, Vittinghoff E, Gottdiener JS \& Newman AB. Subclinical thyroid dysfunction, cardiac function, and the risk of heart failure. The Cardiovascular Health study. Journal of the American College of Cardiology 200852 1152-1159. (doi:10. 1016/j.jacc.2008.07.009)

25 Forfar JC, Muir AL, Sawers SA \& Toft AD. Abnormal left ventricular function in hyperthyroidism: evidence for a possible reversible cardiomyopathy. New England Journal of Medicine 1982 307 1165-1170.

Received 22 June 2010

Accepted 28 June 2010 